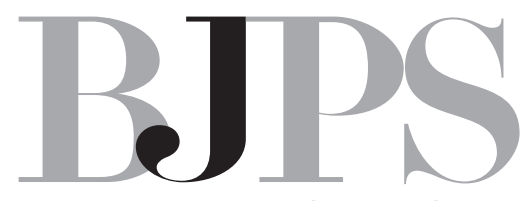

\title{
Pharmacists and their new and important conquest!
}

After many years of fighting, looking for a dream coming true, the Brazilian pharmaceutical community was awarded with the law 13.021, which was published August 11th, 2014, and entered into force September 25th, 2014. According to this important regulation, the pharmacies and drugstores are now considered a health unity. This completely changes, and improves, the relationship between the society and the pharmacists once the pharmacies and drugstores move from a business establishment to a place for pharmaceutical care and assistance, which means health assistance. It is worth to note that in this new model, the rational use of medicines is promoted thanks to the pharmacists' expertise. Besides, it helps implementing other activity of pharmacists, the drug prescription, which was approved more than one year before.

After Dr Pedro Menegasso, the president of Pharmacy Council in Sao Paulo, "people will be now supported by the pharmacist, the only professional in the pharmacy able to dispensing medicines and orienting the patient's treatment. This is an advance".

This essential conquest implies not only the pharmacists' importance acknowledgment but also highly increases their responsibility as health promoter agents! This responsibility, although intrinsic, must have a counterpart from a better higher education, which means the improvement of quality and modernization of pharmacy schools all over the country.

In relation to pharmaceutical education is essential to highlight the efforts of the International Pharmaceutical Federation (FIP) towards the assessment and proposal of any necessary changes. It became clear that the pharmacist must also play a clinical role, integrating the multidisciplinary health care team, contributing to the solution of community health problems especially with the use of drugs.

Pharmaceutical assistance, as defined by the law, is "a set of actions and services, which aim at ensuring the integral therapeutic assistance and the promotion, protection and recovery of the health in public and private establishment that develop pharmaceutical activities". This area must be emphasized in the pharmaceutical curriculum, giving the professional conditions to better performing the activities towards the benefit of health society.

On the other hand, it is also highly relevant to stress the role of academia in this context. The development of research in the area of pharmaceutical assistance/pharmaceutical care is gradually increasing in 


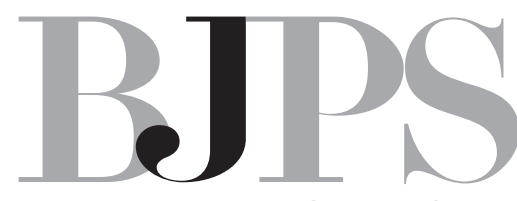

Brazilian Journal of Pharmaceutical Sciences

Brazil and must be strongly strengthened, considering the new scenario of the pharmacies/drugstores after the law 13.021 approval. Based on high quality, the scientific studies can substantially give new approaches to this area, contributing to the improvement of the health system.

BJPS has published many papers about pharmaceutical assistance/pharmaceutical care last five years, which reflects the increasing interest of developing research in this area.

As a Journal that mainly represents the Brazilian scientific community work in Pharmaceutical Sciences, all the efforts will be make to better contributing to face the challenge of transforming good research into the improvement of quality of life!

Congratulations to the pharmacists and to the Brazilian Health System!

\author{
Elizabeth Igne Ferreira \\ Scientific Editor
}

Silvia Storpirtis

Associate Editor 